\title{
EXPERIMENTAL STUDY ON SEISMIC PERFORMANCE OF THREE- DIMENSIONAL BEAM TO COLUMN CONNECTION WITH T-STUB
}

\author{
Xin $B U^{1,2^{*}}$, Qian $G U^{1}$, Xinwu $W A N G^{2}$ \\ ${ }^{1}$ School of Civil Engineering and Architecture, Wuhan University of Technology, Wuhan, Hubei 430000, China; \\ ${ }^{2}$ Department of Civil Engineering, Luoyang Institute of Science and Technology, Luoyang, Henan 471023, China. \\ *Corresponding author: Xin BU \\ Email: buxinbx2011@163.com
}

\begin{abstract}
To study the seismic performance of semi-rigid beam to column connection with T stubs in steel frame, three types of joints in spatial frame and two types of joints in planar frame were used for the investigation. Models of interior joints, exterior joints and corner joints in 3D frame connected with bolts and $\mathrm{T}$ stubs, as well as interior joint and exterior joint of planar frame connected with bolts and T stubs were subjected to pseudo static tests and loads were applied at the column ends. In the tests, deformation characteristics, plasticity development and destructive patterns of the different types of joints were analyzed. Strength, rotational stiffness, hysteretic behaviour, ductile coefficient and energy dissipation capacity of these joints were analyzed. The differences of the mechanical properties of these joints were studied; also, the mechanical properties of these joints in the steel frames were analyzed. The test results demonstrated that under spatial loads the different influences were affected the mechanical properties of these semirigid joints and verified that the mechanical properties of the joints at different locations in steel frames are different.
\end{abstract}

Keywords: Spatial semi-rigid connections; T-stub; Semi-rigid connection; Quasi-static test; Seismic performance.

\section{Introduction}

In earthquakes, a number of steel moment-frame buildings were found to have experienced brittle fractures of beam-to-column connections, which can result in severe damages. Therefore, since the earthquakes occurred at Northridge, California, U.S.A., in 1994 and at Kobe, Japan, in 1995, numerous studies have been carried out by many researchers to study the earthquake-resistance performances of semi-rigid beam to column connection[1-8]. To solve the practical issues of the beam to column connections, the experts have devised a series of tests to study the seismic performance of related typical semi-rigid beam to column connections in planar steel frame. Two limitations are mainly presented in current studies. Firstly, these studies are mainly designed for connections in planar frames, i.e., for frame's columns made from hotrolled $\mathrm{H}$ sections, only the load applied to the planar joints on the major axis, where the bending stiffness is considerably greater than that on the minor axis, is taken into consideration, while the influences of the load applied to the minor axis, where the bending stiffness is smaller, and of the actual force state of the joints in 3D frame is ignored. Secondly, according to the different locations in 3D frame, the joints can be divided into the following three types: interior joints, exterior joints and corner joints (Fig. 1). However, most of the current studies are focused on exterior joint in planar frame, and the effect brings about by the locations of the joints in the frame on the mechanical properties are not taken into consideration. Based on the above, in earthquake, the three types of joints are under loads from more than one direction in 3D frame. These connections are subjected to bending moments, torsion moment, shear forces and axial force passing from the beams to the column in several directions. As a result of the combined effects of these internal forces, the performances and destruction mechanisms of the three types of the joints in 3D frame are very complicated [9-12]. Therefore, studying the seismic performance of these joints that are under loads from two directions is important in terms of enhancing the design of steel frame systems and improves the earthquake resistance performance.

The three types of joints in 3D frame shown in Fig. 1 are selected for the pseudo static tests. This study was carried out according to the conditions of actual loads and took into consideration the axial pressures and the loads applied on the columns of the joint in two directions. 
An orthogonal loading device and related counterforce device, as well as restraint devices at the ends of the beam and columns in frame, which can function as the hinged support for the point of inflection, were used to simulate the loads on the joints so as to study their earthquake-resistance performances. To study the differences between the loads on the joints in planar and 3D frames, pseudo static tests were also carried out on exterior joint and interior joint in planar frame, the two types of joints that correspond to those in 3D frame.

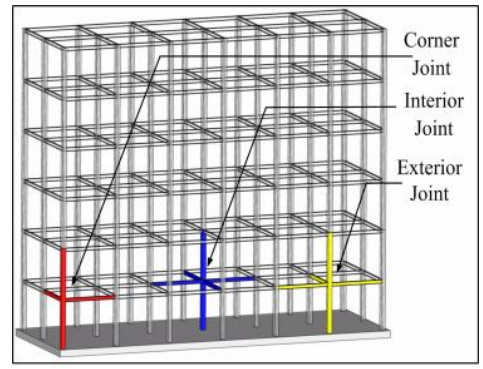

Fig.1 Joints Classification

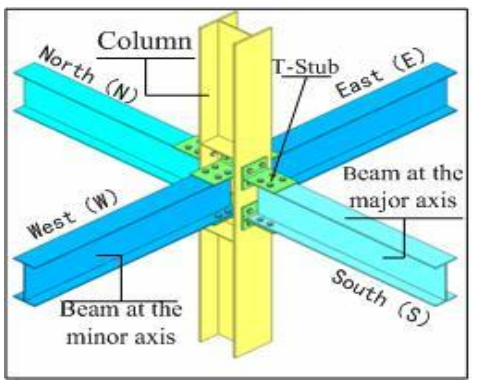

Fig. 4 3D Interior joint

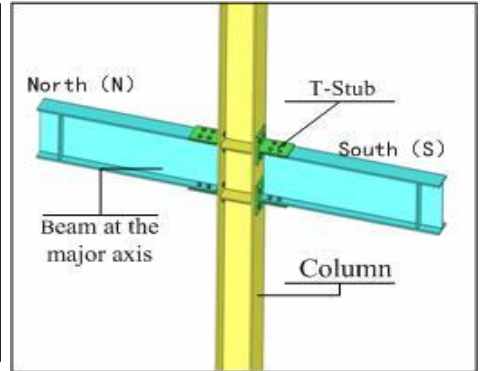

Fig.2 2D Interior joint

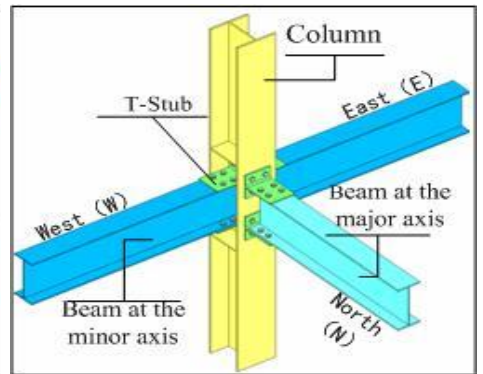

Fig.5 3D Exterior joint

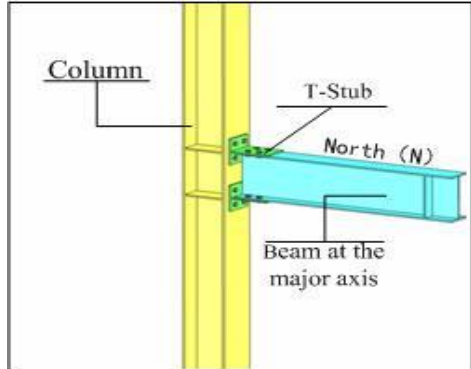

Fig.3 2D Exterior joint

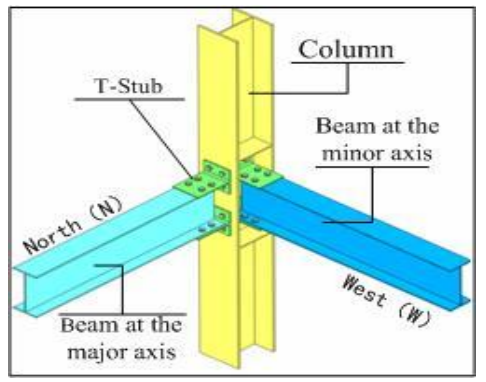

Fig. 63 D Corner joint

\section{Design of the Test Specimens}

Beam to column connection with T stub is one of the typically semi-rigid beam-column connections, and they feature in large rotational stiffness and bearing capacity. As shown in Fig. 1, pseudo static tests were carried out on the three types of joints in 3D frame with $\mathrm{T}$ stub. Meanwhile, to study the different characteristics about the joints in planar frame and 3D frame, pseudo static tests were also carried out on the two types of joints in the planar frame. The models for all the test specimens were made at a scale of 1:1.The beams of the spatial joints were connected to the columns with $\mathrm{T}$ stubs and highstrength bolts. In the plane of the joint's major axis, the beams were connected to the column flanges.
In the plane of the minor axis, the beams were connected to the column web. See Figs. 4 and 6 for the diagrams of the joints in 3D frame. See Figs. 2 and 3 for the interior joint, exterior joint in planar frame, which correspond to the joints in 3D frames.

Columns and beams in the test were made from WH300 $\times 300 \times 10 \times 15$ and $\mathrm{NH} 350 \times 175 \times 7 \times 11$ hot

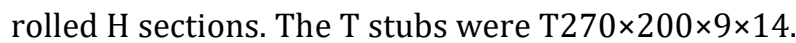
See Table 1 for detailed information about the joints. All the test specimens at the joints were connected with high strength friction bolts (Grade 10.9, M22). The beams and columns were connected in accordance with the Code for Acceptance of Construction Quality of Steel Structures (GB502052001).

\begin{tabular}{|c|c|c|c|c|c|}
\hline $\begin{array}{c}\text { Joint } \\
\text { ID }\end{array}$ & $\begin{array}{c}\text { Length of column } \\
(\mathrm{mm})\end{array}$ & $\begin{array}{c}\text { Length of the beam } \\
\text { at the major axis } \\
(\mathrm{mm})\end{array}$ & $\begin{array}{c}\text { Length of the beam } \\
\text { at the minor axis } \\
(\mathrm{mm})\end{array}$ & $\begin{array}{c}\text { Bolt } \\
\text { Spec. }\end{array}$ & $\begin{array}{c}\text { Bolt } \\
\text { Qty. }\end{array}$ \\
\hline PBJD & 3000 & 1800 & - & $\mathrm{M} 22$ & 16 \\
\hline PZJD & 3000 & 1800 & - & $\mathrm{M} 22$ & 32 \\
\hline KZJD & 3000 & 1800 & 1900 & $\mathrm{M} 22$ & 56 \\
\hline KBJD & 3000 & 1800 & 1900 & $\mathrm{M} 22$ & 40 \\
\hline KJJD & 3000 & 1800 & 1900 & $\mathrm{M} 22$ & 32 \\
\hline
\end{tabular}

All beams, columns, and T stubs were made from Q235B steel from the same lot. The steel has been made into test specimens according to Metallic
Material Room Temperature Tension Test Methods (GB/T288.1-2010) for the strain-stress curve single 
axis tension tests. See Table 2 for the outcome of the

steel's mechanical performance tests.

Table 2. Mechanical performances of the steel used for the test

\begin{tabular}{|c|c|c|c|c|}
\hline \multirow[t]{2}{*}{ Steel category } & \multicolumn{4}{|c|}{ Test item } \\
\hline & $f_{y}(M P a)$ & $f_{y}(M P a)$ & $f_{y}(M P a)$ & $f_{y}(M P a)$ \\
\hline $\begin{array}{l}\text { Columns' web and flange average } \\
\text { value of tensile strength }\end{array}$ & 271 & 457 & 36 & 209 \\
\hline $\begin{array}{l}\text { Beam s' web and flange average value } \\
\text { of tensile strength }\end{array}$ & 270 & 460 & 28.5 & 209 \\
\hline $\begin{array}{l}\text { T stubs' web and flange average value } \\
\text { of tensile strength }\end{array}$ & 260 & 456 & 36.5 & 207 \\
\hline
\end{tabular}

\section{Test Devices}

At present, pseudo static tests for joints are mainly carried out in two ways: loads applied to beam ends and loads applied to column ends, as shown in Fig. 7 (a) and (b). The method of application to the beam ends can be realized more easily and basically consistent with the actual forced state of beam to column connection. However, this method does not take into account the P- $\triangle$ second-order effect on the column. On the other hand, the method of application at column end can comprehensively show the forced state of beam to column connection.

Therefore, the method of application at column ends was adopted in this study. On the basis of the mechanical characteristics of beam to column joints in 3D frame, two pairs of horizontal actuators were separately placed in the joints' major axis plane and minor axis plane. The two planes were orthogonal to each other. Each pair of actuators was fixed to a Lshaped reaction wall, and horizontal loads were applied to both ends of the column. A vertical actuator fixed with a reaction frame was arranged at

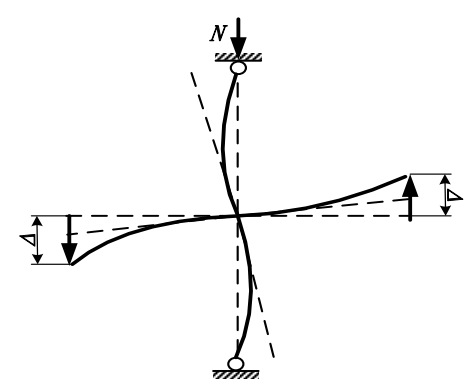

(a) Load are applied to the beam end of the joint the top of the column so that axial pressure can be applied on column. The vertical actuator can horizontally move with the end in both directions.

The above five actuators were controlled by an electro hydraulic servo testing system. The northsouth direction was the joint's major axis plane, and the east-west direction was the minor axis plane. At the foot of the column, a hinged support that was able to move in all directions was used to achieve slide displacement due to orthogonal loads in two directions. Hinged supports that were able to follow the movement of the beam ends were arranged at the beam ends in the east (E), west (W), north $(N)$, and south (S) directions. The supports were hinged in the plane of the applied loads and moved with the ends out of the planes of loads. Meanwhile, pressure sensors were placed at the upper and lower ends of each beam to measure the reaction force of the supports at the beam ends. Each of the beam-end supports was placed on a lattice truss that has large stiffness. See Figs. 8 for the test sites of the joint specimen.

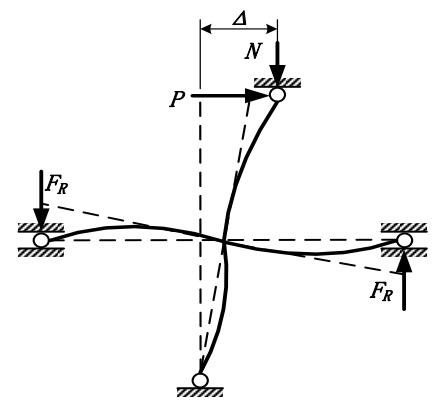

(b) Load are applied to the column end of the joint Fig. 7 Mechanical models at the beam to column joints for the pseudo static tests.

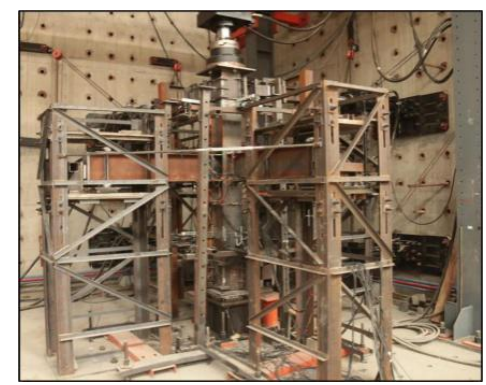

(a) $3 D$ interior joint test site

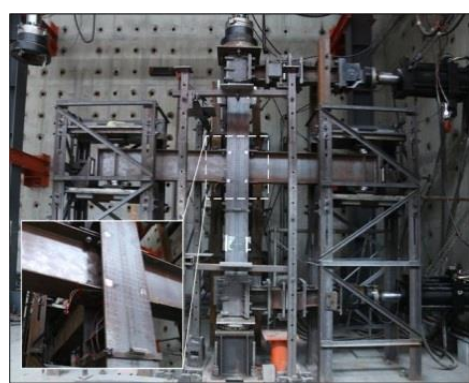

(b) $3 D$ exterior joint test site Figure 8. Spatial joints test site

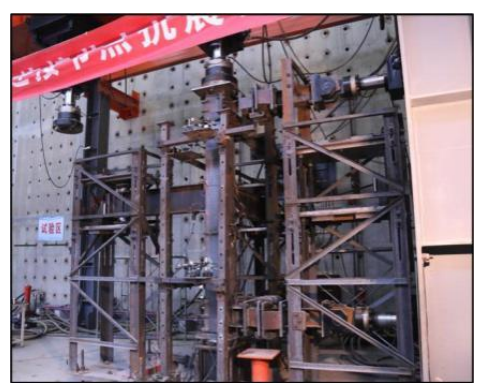

(c) $3 D$ corner joint test site 


\section{Loading Scheme and Measurement Scheme}

In the tests, the two symmetric axes on the steel column's cross section were the directions of loads.

According to the standard rules of FEMA461 for evaluating earthquake-resistance performances of steel structural members, the cyclic loads were applied to the major axis and minor axis by repeatedly controlling the displacement. The load curve of the test is shown in Fig.9. Firstly, a $200 \mathrm{kN}$ axial force was applied on the column top from the vertical actuator to simulate the axial pressure on the column. During the entire test, the axial pressure was kept the same. After the test piece stabilized under axial pressure, horizontal displacement loads were applied. The push by the actuator was the positive direction, and the pull was negative direction. The upper and lower actuators on the major axis plane applied displacement loads in reverse directions to the top and bottom of the column. The actuators on the minor axis remained motionless. Each level of loads was applied to the positive and negative directions in turn for three cycles.

After the loads were applied, the actuators in the direction of the major axis were reset to the zero

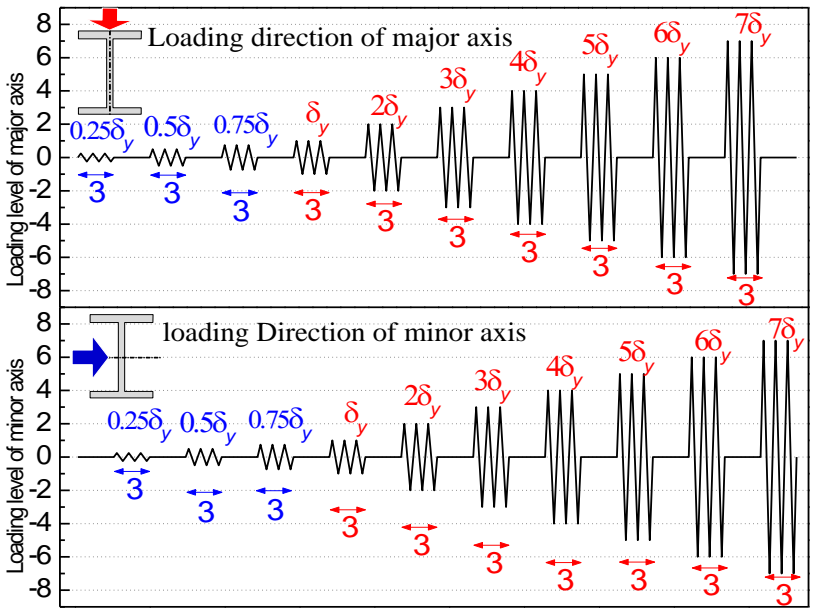

Figure 9. Test loading history

\section{Analysis of the Test Results}

\subsection{Test phenomena}

In the tests, the beam to column connection with $\mathrm{T}$ stub featured in semi rigidity with quite large ductility, no matter the $\mathrm{T}$ stubs were used in planar or $3 \mathrm{D}$ joints. The main feature of destruction is that after the $\mathrm{T}$ stubs are severely deformed, they lose position, and the upper and lower actuators on the minor axis started to apply displacement loads respectively at the same time in reverse directions to the top and bottom of the column where the test specimen was fixed. The actuators in the direction of the major axis remained motionless. The test was stopped if any joint broken, any obvious buckling failure was found, or the bearing capacity in the hysteretic curve monitored during the test dropped. To measure the relative rotation between the beam and column of a 3D connection, guyed displacement meters were placed at the angles between the beams in all directions and the column in all directions to measure the relative displacement between them. The measured relative displacements were converted into the relative rotation between the beams and the column by using the formula shown in Fig. 10. Pressure sensors were placed at the top and bottom of each beam to collect data of counter forces at the supports on the beam's end. While deformation due to quasi-static cyclic loads the connection area was taken into consideration, the strain gauges and rosettes were put on the web and flanges of the $\mathrm{T}$ stubs, beams and columns to monitor the deformation in this area.

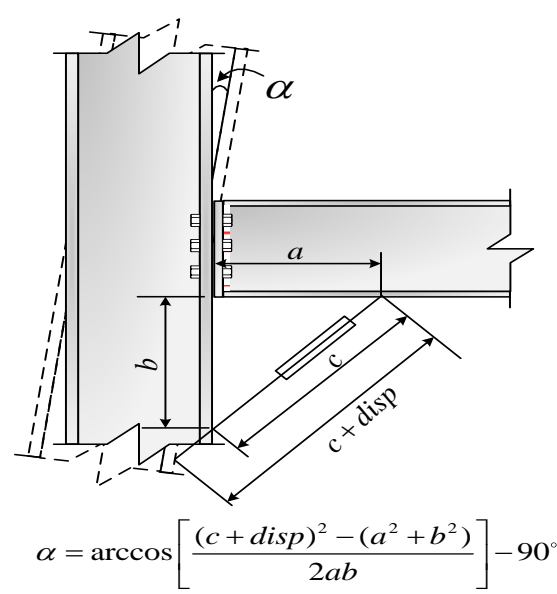

Figure 10. Measurement method of relative rotation

their bearing capacities. They undergo a similar process of destruction: at the junction of T stubs' web and flange yield $\rightarrow$ the $\mathrm{T}$ stubs' flange is bent under tensile $\rightarrow$ the plastic area where the junction of T stubs' web and flange expand and form plastic hinge $\rightarrow$ T stub's web and flange junction fracture. For the test specimen at the planar exterior joint (PBJD) under the cyclic load, larger plastic deformations were found at the junction of T stub's web and flange and the $\mathrm{T}$ stub were subjected to 
reasonably large pulls and pressures due to the cyclic load, after the cyclic load junction of T stub's web and flange fracture (Fig. 11). Due to the cyclic load, the $\mathrm{T}$ stubs on both sides of the column at the planar interior joint (PZJD) not only became quite plastic and deformed but also transmitted the internal forces into the centre of the joint so that the column's web panel caused shear deformation (Fig. 12). The spatial interior joint (KZJD) and the exterior joint (KBJD) in 3D frame have the same features of destruction. The feature of destruction in the joint's major axis plane was mainly that the $\mathrm{T}$ stubs' flanges bend and break away from the column's flanges, but the deformation does not affect the bearing capacity of the joint's major axis plane. Destruction in the plane of the minor axis occurred at the junction of column's web and flange and was shown as the web tore apart.

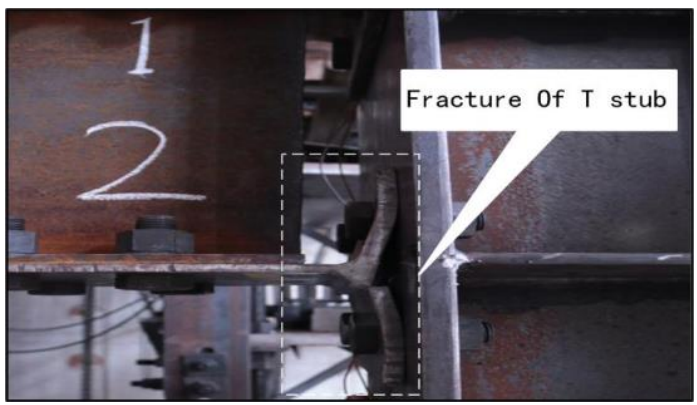

Figure 11. Destruction of Specimen PBJD.

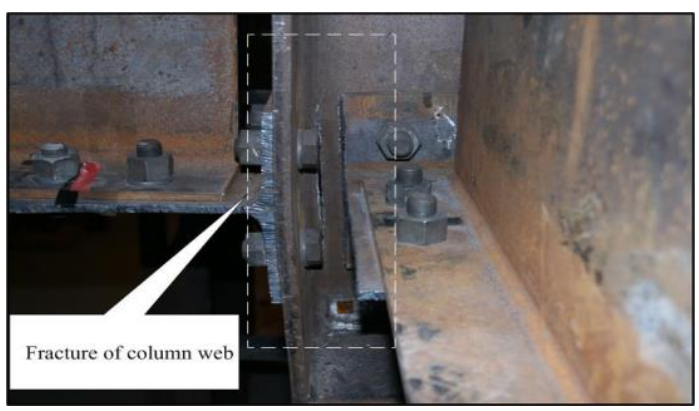

(a) Lift side
The main reason was that at the interior and exterior joints the two beams are connected to the column's web in the direction of the minor axis. The flanges of the $\mathrm{T}$ stubs were thicker than the column's web, and therefore, when the plane of the minor axis was under load, the $\mathrm{T}$ stubs on both sides of the column's web caused the column's web to deform in the opposite direction outside of the plane due to the pull and press effects. destruction of cracks showed in Figs. 13-14. For the spatial corner joint (KJJD), only one beam was respectively connected to the column in the minor axis plane and the major axis plane. The pressing brought about by the $\mathrm{T}$ stubs to the column web in the central area was reduced; therefore, destruction occurred at the major axis plane and was shown as the $\mathrm{T}$ stub fracture (Fig. 15).

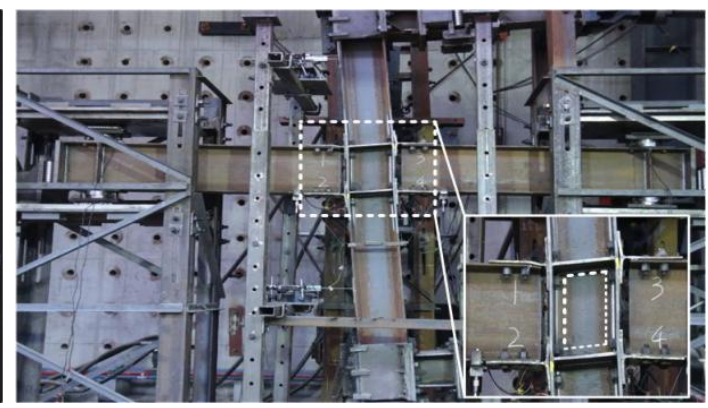

Figure 12. Destruction of Specimen PZJD.

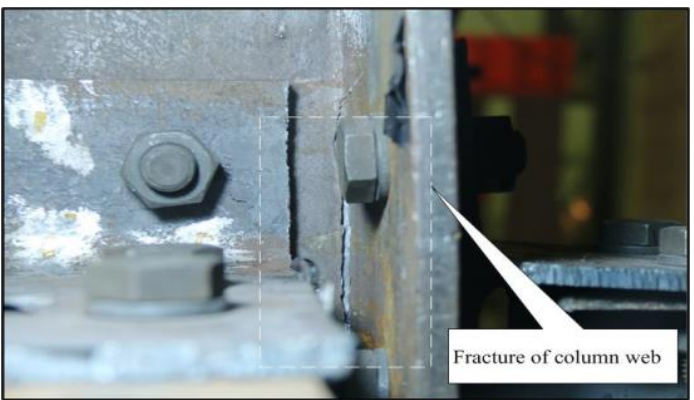

(b) Right side

Figure 13. Fracture of Column's web for Specimen KZJD

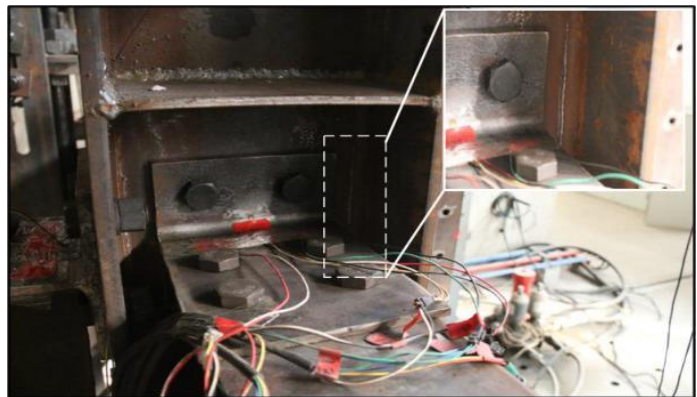

Figure 14 Destruction of Specimen KBJD.

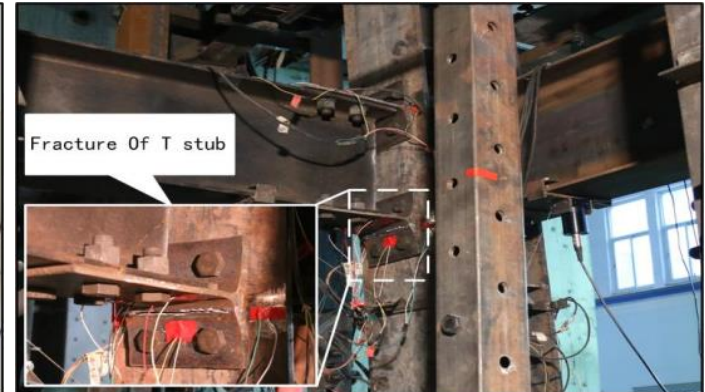

Figure 15. Destruction of Specimen KJJD. 


\subsection{Analysis of the hysteretic curves}
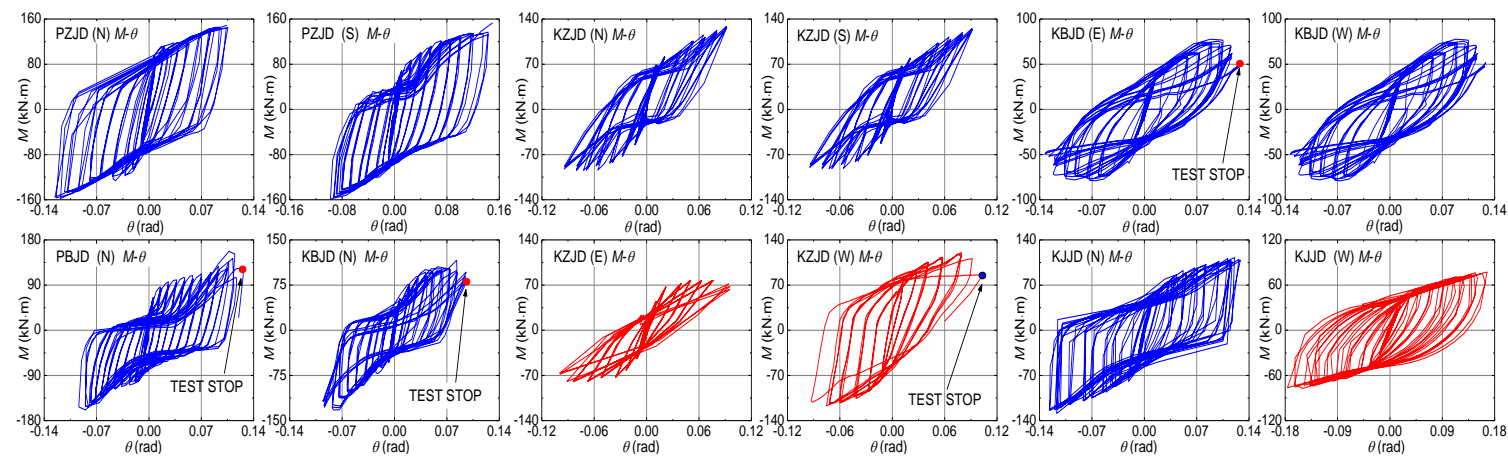

Figure 16. Hysteretic curves for all Specimens

The hinged supports' counterforce data collected in the tests from the pressure sensor at the top and bottom of each beam were converted to bending moments at the ends of the beams in connection area. The data of the relative displacements between the beams and column in all directions, which were collected with the guyed displacement meters, were calculated and converted to the relative rotation between the beams and column to obtain hysteretic curves of the $M-\theta$ of the joints in all directions (Fig. 16). From the diagrams, it is shown that the hysteretic curves of most of the test Specimens were in a shuttle shape without any pinch effect, which means that the connection with $\mathrm{T}$ stubs had reasonably good hysteretic characteristics. As the column's web bent when the minor axis plane was under loads, the hysteretic curves of the spatial interior joint (KZJD) in the east and west directions in were different from each other, and the bearing capacity at the west side of the joint (KZJD) decreased due to the tear in the column's web. According to the curve, the bearing capacity of the interior joint (PZJD) in planar frame and the interior joint (KZJD) in 3D frame in the major axis direction did not decrease, indicating that the these two connection had large bearing capacities. While the fact that the two beams in the minor axis plane under loads was taken into consideration, the hysteretic curves in the north and south directions of the major axis of the interior joint (KZJD) in 3D frame were less full than those of the interior joint (PZJD) in planar frame, which indicates that when the minor axis plane of the joints were under loads, the hysteretic characteristics of these joints in the major axis plane were affected. As the column's web bent when the minor axis plane was under loads, the hysteretic curves of the spatial interior joint (KZJD) in the east and west directions were different from each other, and the bearing capacity at the west side of the joint (KZJD) decreased due to the tear in the column's web. According to the curve, the bearing capacity of the interior joint (PZJD) in planar frame and the interior joint (KZJD) in 3D frame in the major axis direction did not decrease, indicating that these two connection had large bearing capacities. While the fact that the two beams in the minor axis plane under loads was taken into consideration, the hysteretic curves in the north and south directions of the major axis of the interior joint (KZJD) in 3D frame were less full than those of the interior joint (PZJD) in planar frame, which indicates that when the minor axis plane of the joints were under loads, the hysteretic characteristics of these joints in the major axis plane were affected. The hysteretic curve at the north side of the 3D exterior joint's (KBJD) major axis and the hysteretic curve at the north side of the planar exterior joint (PBJD) showed decreased bearing capacities due to the fracture of $\mathrm{T}$ stubs. The 3D exterior joint's (KBJD) the hysteretic curve at the north side of its major axis plane was not as full as that of the planar corner joint (PBJD). And also the hysteretic curve of the 3D corner joint's (KJJD) major axis was not as full as 
that of the planar corner joint (PBJD). According to the above analysis, for semi rigid beam to column joints in 3D frames where $\mathrm{T}$ stubs are used for connection, the hysteretic characteristics of the joints' major axis planes decrease when the minor axis's planar loads are taken into consideration. For

\subsection{Analysis of skeleton curves}

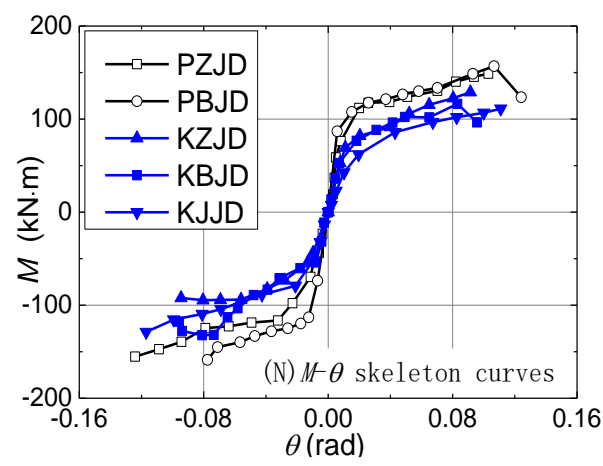

(a) Skeleton curves of north side

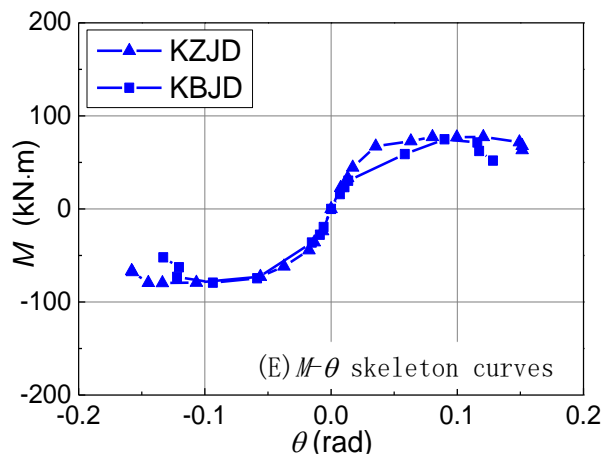

(c) Skeleton curves of east side the joints in both spatial and planar frames, the joints in the frame have different stiffness due to their different locations, which would affect the hysteretic characteristics of the 3D joints in the major axis plane and minor axis plane.

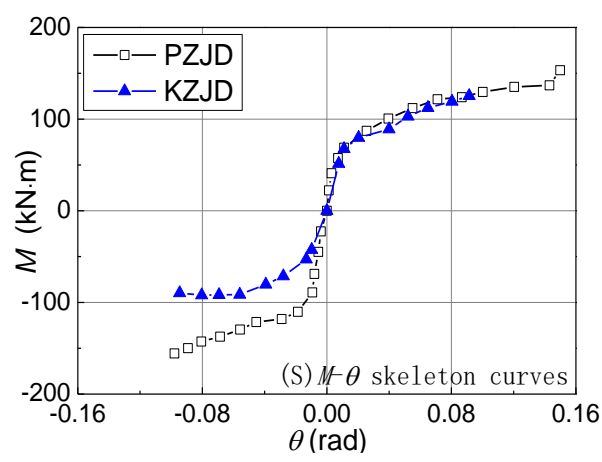

(b) Skeleton curves of south side

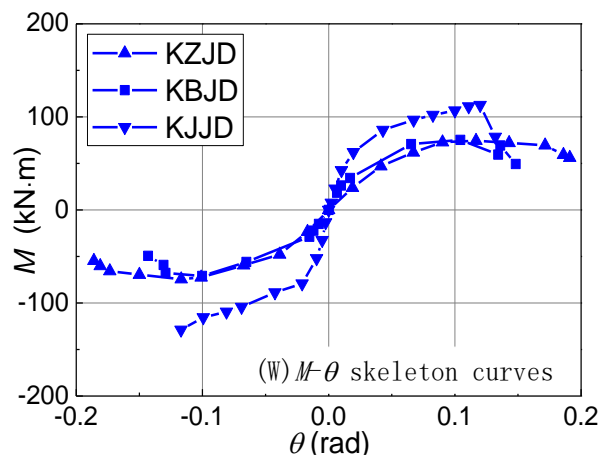

(d) Skeleton curves of west side

Fig 17 Skeleton curves of test specimens

The skeleton curves of the test specimens at the joints in all directions are shown in Fig. 17. The skeleton curves of the joints have a reversed $\mathrm{S}$ shape, which means that the test pieces have gone through the following three typical phases due to the quasi-static cyclic loads: elasticity, plasticity and limit destruction. See Table 4 for the yield rotation that corresponds to yield moment and limit rotation that corresponds to limit moment of the test specimens at the joints in all directions. The ratios between the $M_{u}$ and $M_{y}$ of the joints in all directions are in the range of 1.71-5.13, which indicates that the bearing capacities of the joints that are connected with $\mathrm{T}$ stub basically increased from the yield state to limit state. According to Table 4, it is concluded that the bearing capacities of the planar joints are higher than those of the 3D joints. While the loads applied to the minor axis plane are taken into consideration, the bearing capacities of the major axis in 3D joints decreased. By analyzing the data in Table 4, it can be concluded that the limit moments in the minor axis plane of the 3D joints are lower than those in the major axis plane. It is shown in Fig. 19(c) and (d) that the skeleton curves of the 3D interior joints (KZJD) and 3D exterior joints (KBJD) in the positive and negative directions on the east and west sides almost coincide with each other, which means that their yield moments and limit moments are not very different from each other. The skeleton curves at the west side of the 
plane minor axis plane of the 3D corner joint (KJJD) is higher than that of the $3 \mathrm{D}$ interior joint (KZJD) and the 3D exterior joint (KBJD). This is mainly because one frame beam is connected to the column's web in the minor axis plane of the corner joint, while for the interior joint and exterior joint, two beams are connected to the column's webs. When loads are applied on the minor axis plane, the webs at the interior joint and the exterior joint are under pressures from both sides, which will easily bend them out of the plane and deform so as to lose its bearing capacity. As the column's web at the 3D corner joint (KJJD) is under loads on one side, it bent and deformed less outside of the plane so that its bearing capacity is higher than that of the 3D interior joint (KZJD) and 3D exterior joint (KBJD).

Table 4 Test results

\begin{tabular}{|c|c|c|c|c|c|c|c|}
\hline \multirow{2}{*}{ Joint ID } & \multirow{2}{*}{ Beam ID } & \multirow{2}{*}{ Loading direction } & \multicolumn{2}{|c|}{ Yield stage } & \multicolumn{2}{|c|}{ Limit stage } & \multirow{2}{*}{$\frac{M_{u}}{M_{y}}$} \\
\hline & & & $M_{y} / \mathrm{kN} \cdot \mathrm{m}$ & $\theta_{y} / \mathrm{rad}$ & $M_{u} / \mathrm{kN} \cdot \mathrm{m}$ & $\theta_{u} / \mathrm{rad}$ & \\
\hline \multirow{2}{*}{ PBJD } & \multirow{2}{*}{ North } & positive & 49.94 & 0.0058 & 157.24 & 0.1070 & 3.15 \\
\hline & & negative & -73.68 & -0.0068 & -158.75 & -0.0848 & 2.15 \\
\hline \multirow{4}{*}{ PZJD } & \multirow{2}{*}{ North } & positive & 76.38 & 0.0081 & 148.79 & 0.1040 & 1.95 \\
\hline & & negative & -69.60 & -0.0112 & -157.85 & -0.1180 & 2.27 \\
\hline & \multirow{2}{*}{ South } & positive & 68.76 & 0.0115 & 153.37 & 0.1500 & 2.23 \\
\hline & & negative & -89.13 & -0.0092 & -158.50 & -0.0980 & 1.78 \\
\hline \multirow{8}{*}{ KZJD } & \multirow{2}{*}{ North } & positive & 61.89 & 0.0110 & 128.88 & 0.0910 & 2.08 \\
\hline & & negative & -49.46 & -0.0130 & -92.27 & -0.0950 & 1.87 \\
\hline & \multirow{2}{*}{ South } & positive & 61.89 & 0.0110 & 125.37 & 0.0910 & 2.03 \\
\hline & & negative & -49.46 & -0.0130 & -92.08 & -0.0800 & 1.86 \\
\hline & \multirow{2}{*}{ East } & positive & 23.29 & 0.0130 & 76.96 & 0.1210 & 3.3 \\
\hline & & negative & -24.82 & -0.0130 & -79.41 & -0.1450 & 3.2 \\
\hline & \multirow{2}{*}{ West } & positive & 23.73 & 0.0180 & 120.29 & 0.0790 & 5.07 \\
\hline & & negative & -22.84 & -0.0170 & -117.20 & -0.0750 & 5.13 \\
\hline \multirow{6}{*}{ KBJD } & \multirow{2}{*}{ North } & positive & 52.67 & 0.0071 & 116.32 & 0.0831 & 2.21 \\
\hline & & negative & -54.09 & -0.0079 & -132.27 & -0.0810 & 2.45 \\
\hline & \multirow{2}{*}{ East } & positive & 30.24 & 0.0132 & 77.68 & 0.0877 & 2.57 \\
\hline & & negative & -35.97 & -0.0152 & -77.97 & -0.0936 & 2.17 \\
\hline & \multirow{2}{*}{ West } & positive & 33.95 & 0.0169 & 74.26 & 0.1045 & 2.19 \\
\hline & & negative & -29.13 & -0.0138 & -73.99 & 0.0979 & 2.54 \\
\hline \multirow{4}{*}{ KJJD } & \multirow{2}{*}{ North } & positive & 64.05 & 0.0237 & 109.92 & 0.1265 & 1.72 \\
\hline & & negative & -70.41 & -0.0209 & -124.50 & -0.1265 & 1.77 \\
\hline & \multirow{2}{*}{ West } & positive & 43.42 & 0.0294 & 77.30 & 0.1669 & 1.78 \\
\hline & & negative & -44.66 & -0.0327 & -76.28 & -0.1761 & 1.71 \\
\hline
\end{tabular}

\subsection{Analysis of the degradation of rotational stiffness}

Before yielding, tangential stiffness is used to describe the rotational stiffness of beam to column connection, after entering the plastic state, the relationship of $M-\theta$ curve becomes obviously nonlinear. For clarity, the secant stiffness is used to describe the rotational stiffness of beam to column connection. Therefore, Formula (1) will be used to determine the rotational stiffness of connection.

$$
K_{i}=\frac{\left|+M_{i}\right|+\left|-M_{i}\right|}{\left|+\theta_{i}\right|+\left|-\theta_{i}\right|}
$$


$M_{i}$ is the peak value of the moment bearing capacity under certain level of loads, and $\theta_{i}$ is the rotation that corresponds to the peak value of the moment bearing capacity under certain levels of loads.

The initial rotational stiffness at the north and south sides of the planar interior joint (PZJD) are $7563.73 \mathrm{kN} \cdot \mathrm{m} / \mathrm{rad}$ and $7627.53 \mathrm{kN} \cdot \mathrm{m} / \mathrm{rad}$ respectively, and the initial rotational stiffness at the south and north sides in the major axis plane of the corresponding 3D interior joint (KZJD) are both $4639.58 \mathrm{kN} \cdot \mathrm{m} / \mathrm{rad}$. When the loads applied to the minor axis plane of the 3D interior joint (KZJD) are

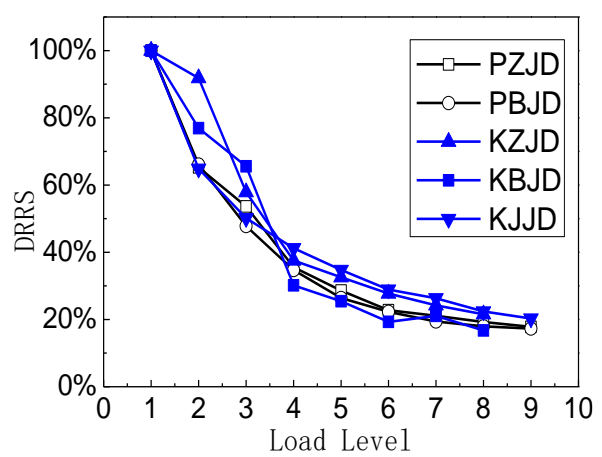

(a) Stiffness degradation curves of north side

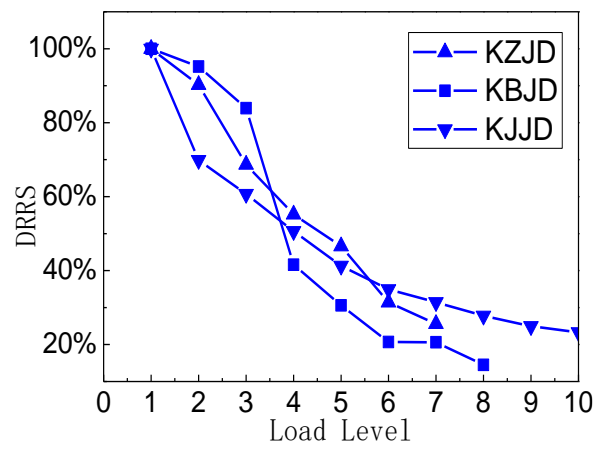

(c) Stiffness degradation curves of east side taken into consideration, the initial rotational stiffness of the major axis is about 38\% lower than that of the planar exterior joint (PZJD).The initial rotational stiffness at the north side of the planar exterior joint (PBJD), 3D exterior joint(KBJD) and 3D corner joint (KJJD) are $9811.11 \mathrm{kN} \cdot \mathrm{m} / \mathrm{rad}$, $7117.33 \mathrm{kN} \cdot \mathrm{m} / \mathrm{rad}$, and $3014.79 \mathrm{kN} \cdot \mathrm{m} / \mathrm{rad}$ respectively. It can be concluded that when the loads applied to the minor axis plane are taken into consideration, the initial rotational stiffness of the major axis of the 3D joints are lower than those of the planar joints.

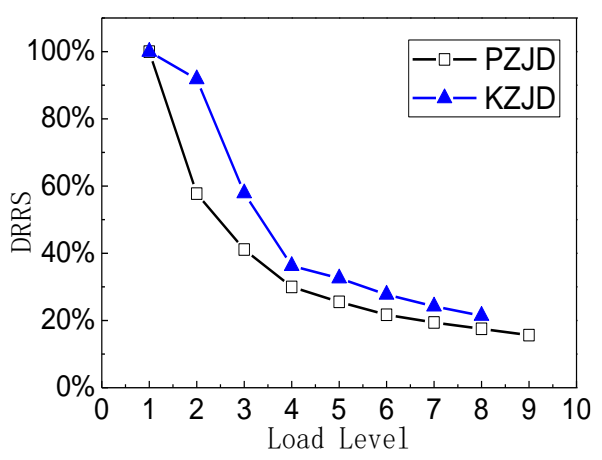

(b) Stiffness degradation curves of south side

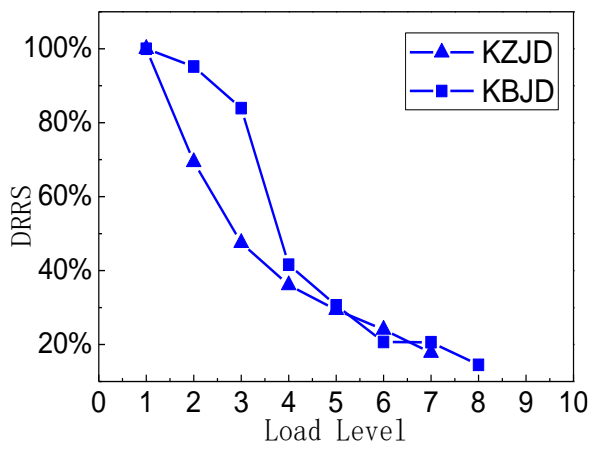

(d) Stiffness degradation curves of west side

Figure 18. Stiffness degradation curves of test specimens

The initial rotational stiffness of all the joints in all directions was generalized. While the load level increased, their rotational stiffness degraded. See Fig. 18 for the curves indicating the degradation of the joints' rotational stiffness with the increasing load. The degradation rate of the rotational stiffness (DRRS) of the planar joints was slightly higher than that of the $3 \mathrm{D}$ joints. When the planar joints were destructed, the rotational stiffness degraded to about $20 \%$ of the initial value. In the minor axis plane of the $3 \mathrm{D}$ joints, the degradation of the rotational stiffness at the east side of the joints showed that when the loads were 4 times less than the yield loads, the degradation rate of the 3D interior joint(KZJD) was higher than that of the exterior joint(KBJD). When the loads were 4 times greater than the yield loads, the degradation rates of the two joints were basically the same. When the 
joints were finally destructed, the rotational stiffness degraded to less than $20 \%$ of the initial value.

\subsection{Ductile coefficient of the rotation}

The ductile coefficient is the ratio of the limit rotation $\theta_{u}$, to the yield rotation, $\theta_{y}$. See Table 5 for the ductile coefficients of the connection in every direction. The ductile coefficient of connection is the average value in the positive and negative directions of the major and minor axis. When the loads of a 3D joints in the minor axis plane are taken into consideration, the ductility of the $3 \mathrm{D}$ joints in the major axis plane decreased. According to the table5, the ductile coefficient of the 3D interior joint
(KZJD) in the major axis plane was $36.17 \%$ lower than that of the planar interior joint(PZJD),and the ductile coefficients of the 3D exterior joint(KBJD) and 3D corner joint(KJJD) at the major axis were $28.98 \%$ and $63.13 \%$ lower than that of the planar exterior joint(PBJD), respectively. Locations of the joints in the frame are taken into consideration for analysis. For the joint at the exterior of the frame, no matter whether they were 3D joints or planar joints, the ductile coefficients of the exterior joint were higher than those of the interior joint. From the above analysis, it can be concluded that the ductile coefficient of the 3D joints was lower than that of the planar joints, and the ductile coefficients of the joints at different locations of the frame were different from each other.

Table 5 Ductility factor

\begin{tabular}{|c|c|c|c|c|c|c|c|}
\hline \multirow{2}{*}{ Joint ID } & \multirow{2}{*}{ Loading direction } & \multicolumn{2}{|c|}{ Major axis } & \multirow{2}{*}{$\begin{array}{c}\text { average } \\
\text { value }\end{array}$} & \multicolumn{2}{|c|}{ Minor axis } & \multirow{2}{*}{$\begin{array}{c}\text { average } \\
\text { value }\end{array}$} \\
\hline & & North & South & & East & West & \\
\hline \multirow{2}{*}{ PZJD } & positive & $(1.3)$ & 13.64 & \multirow{2}{*}{11.75} & 一 & 一 & \multirow{2}{*}{ - } \\
\hline & negative & 10.73 & 10.89 & & - & - & \\
\hline \multirow{2}{*}{ PBJD } & positive & 18.45 & - & \multirow{2}{*}{15.46} & - & - & \multirow{2}{*}{-} \\
\hline & negative & 12.47 & - & & - & - & \\
\hline \multirow{2}{*}{ KZJD } & positive & 8.27 & 8.27 & \multirow{2}{*}{7.5} & 9.31 & 4.39 & $4.40 \sim 10.23$ \\
\hline & negative & 7.31 & 6.15 & & 11.15 & 4.41 & \\
\hline \multirow{2}{*}{ KBJD } & positive & 11.7 & 一 & \multirow{2}{*}{10.98} & 6.64 & 6.18 & \multirow{2}{*}{6.52} \\
\hline & negative & 10.25 & - & & 6.16 & 7.09 & \\
\hline \multirow{2}{*}{ KJJD } & positive & 5.34 & - & \multirow{2}{*}{5.7} & - & 5.68 & \multirow{2}{*}{5.53} \\
\hline & negative & 6.05 & - & & - & 5.39 & \\
\hline
\end{tabular}

\section{Energy dissipation capacity}

For the joints' energy dissipation capacities, the equivalent viscous damping coefficient, $h_{\mathrm{e}}$, is usually used to evaluate the amount of energy absorbed by a test Specimen under cyclic loading. The calculation can be carried out according to Fig. 19.

$$
h_{e}=\frac{1}{2 \pi} \frac{S_{A B C}}{S_{A O D}}
$$

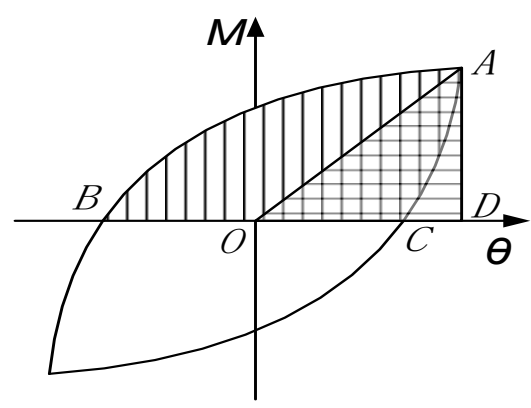

Figure 19. Calculation diagram of $h_{e}$ 
Table 6 Equivalent viscous damp coefficient

\begin{tabular}{|c|c|c|c|c|c|c|}
\hline \multirow{2}{*}{$\begin{array}{l}\text { Joint } \\
\text { ID }\end{array}$} & \multicolumn{3}{|c|}{ Major axis } & \multicolumn{3}{|c|}{ Minor axis } \\
\hline & North & South & $\begin{array}{l}\text { average } \\
\text { value }\end{array}$ & East & West & $\begin{array}{l}\text { average } \\
\text { value }\end{array}$ \\
\hline PZJD & 0.271 & 0.318 & 0.295 & - & - & - \\
\hline PBJD & 0.216 & - & 0.216 & - & - & - \\
\hline KZJD & 0.279 & 0.289 & 0.284 & 0.225 & 0.233 & 0.229 \\
\hline KBJD & 0.244 & - & 0.244 & 0.326 & 0.309 & 0.318 \\
\hline KJJD & 0.285 & - & 0.285 & - & 0.389 & 0.389 \\
\hline
\end{tabular}

See Table 6 for the equivalent viscous damping coefficients of the joints calculated using Formula 2.

The equivalent viscous damping coefficient of a joint is the average value in the positive and negative directions of the major and minor axes. When the loads of the $3 \mathrm{D}$ joint in the minor axis plane were taken into consideration, the equivalent viscous damping coefficient of the 3D interior joint (KZJD) was relatively lower than that of the planar interior joint (PZJD), and the equivalent viscous damping coefficients of the 3D exterior joint (KBJD) and 3D corner joint (KJJD) in the major axis plane were higher than that of the planar exterior joint.

Locations of the joints in the frame were taken into consideration for the analysis. For the 3D interior joint (KZJD) and 3D corner joint (KJJD), the equivalent viscous damping coefficients were not very different and that of the 3D exterior joint

(KBJD) was $14.08 \%$ lower than those of the foregoing joint. The equivalent viscous damping coefficient of the planar exterior joint (PBJD)is $26.78 \%$ lower than that of the planar interior joint. By analyzing the differences between the equivalent viscous damping coefficients of the 3D joints at the major and minor axes, it can be concluded that the energy dissipation capacity of the frame's interior joint (KZJD) at the major axis was greater than that at the minor axis, and the energy dissipation capacities of the 3D exterior joint(KBJD)and the 3D corner joint(KJJD)at the major axis was smaller than those at the minor axis.

On the basis of the above analyses, when the impact of loads on the joint in the minor axis plane and the locations of the joints at the frame are taken into consideration, they have varying degrees of influence on the joints' energy dissipation characteristics.

\section{Conclusions}

The following conclusion is obtained by the research: (1) The joints with T stub were typical semi rigid connection. This type of connection has a certain bending moment bearing capacity, a reasonably large initial stiffness, and better deformation capacity.
(2) Among the joints, the main feature of destruction of the planar joint and 3D corner joint was the fracture of the T stub, while the destruction of the 3D interior and exterior joints occurred in the minor axis plane and destruction is shown as the column's web are under pressure and torn apart. This means that the deformation characteristics of the connections at the minor axis and major axis were different. For the deformation of the joints at the minor axis, besides the deformation of the T stub, the deformation outside of the plane of the column's web should also be taken into consideration. The deformation outside of the plane of the column's web is not good for the joint's bending resistance characteristics to be fully exerted.

(3) The 3D joints with $\mathrm{T}$ stub were under spatial cyclic loads in two directions so that the joints' moment bearing capacity, hysteretic characteristics, rotational stiffness, and ductile coefficients are lower than plane joints, which means that the models of the joints and the spatial effects of the loads have quite large influences on mechanical characteristic of the connection.

(4) For both planar joints and 3D joints, the different locations in the frame led to different mechanical characteristics of the joints. This is mainly because the joints at different locations contributed differently to the overall stiffness of the frame.

\section{References}

[1] Hao Jiping, Li Wenling. Finite element analysis for the top-and-seat angle minor axis connection of semi-rigid steel beam-column joints. China Civil Engineering Journal, 2007,09:36-42. (in Chinese)

[2] Wang Zhan, Wang Tao. Experiment and finite element analysis for the end plate minor axis connection of semi-rigid steel frames. China Civil Engineering Journal, 2012, 08:83-89. (in Chinese)

[3] Wang Yan, Feng Shuang, Wang Yutian. Experimental study on hysteretic behaviour for rigid-reinforced connections. China Civil Engineering Journal, 2012, S1:96-101. (in Chinese)

[4] Wang Yan, Mao Hui. Study on Seismic Performance of the End Beam Expand Flange 
Connection. China Civil Engineering Journal,2012,S1:96-101. (in Chinese)

[5] Shi Wenlong, Li Guoqiang, Xiao Yong et al.Cyclic Loading Tests on Composite Beam-to-Column Joints with Semi-rigid Connections. Journal of Building Structures,2008,05:57-66. (in Chinese)

[6] Li Zeshen, Li Xiumei, Zheng Xiaowei. Experimental study and numerical investigation on hysteretic behaviour of T-stub semi-rigid beam-to-column connections. Journal of Building Structures, 2014,07:61-68. (in Chinese)

[7] Li Feng xia,Bu Xin,Wang Xinwu.Research on Hysteretic Behaviour of the Slit T Steel BeamColumn Connections. Building Science,2010,05:28-32. (in Chinese)

[8] Wang Xinwu. Research on Beam-to-Column Connections of Steel Frame.Wuhan University of Technology.2003. (in Chinese)

[9] Fan Jiansheng, Zhou Hui, Nie Jianguo et al. Experimental study on seismic performance of three-dimensional composite beam-to-column joints. China Civil Engineering Journal, 2014,04:47-55. (in Chinese)
[10] Fan Jiansheng, Zhou Hui, Nie Jianguo et al. Experimental study on seismic performance of three-dimensional composite beam-to-column joints. Journal of Building Structures,2011,12:3745. (in Chinese)

[11] Kawaguchi J, Morino S, Sugimoto T. Elastoplastic behaviour of concrete-filled steel tubular three dimensional sub assemblages. Proceedings of an Engineering Foundation Conference. Reston VA,USA:ASCE,1992:726-741.

[12] Nishiyama I. Seismic test facility for three dimensional beam-to-column sub assemblages. Tachihara: Building Research Institute. Department of Production Engineering,1999.

[13] FEMA-350 Recommended seismic design criteria for new steel structural buildings[S].2000

[14] FEMA-351 Recommended seismic evaluation and upgrade criteria for existing welded steel moment-frame buildings[S].2000

[15] FEMA-461 Interim Testing Protocols for Determining the Seismic Performance Characteristics of Structural and Non-structural Components[S].2007 